\title{
Dashboards for Real-time Monitoring of Winter Operations Activities and After-action
}

Assessment

Jairaj Desai - Corresponding Author

Purdue University

207 S Martin Jischke Dr, West Lafayette, IN 47907

Phone: 765-607-3972

Email: desaij@purdue.edu

https://orcid.org/0000-0003-2885-203X

Jijo K. Mathew

Purdue University

207 S Martin Jischke Dr, West Lafayette, IN 47907

Phone: 765-494-4521

Email: kjijo@purdue.edu

\section{Woosung Kim}

Purdue University

207 S Martin Jischke Dr, West Lafayette, IN 47907

Phone: 812-369-0084

Email: kim898@purdue.edu

\section{Mingmin Liu}

Purdue University

207 S Martin Jischke Dr, West Lafayette, IN 47907

Phone: 812-241-2257

Email: liu2622@purdue.edu

\section{Howell Li}

Purdue University

207 S Martin Jischke Dr, West Lafayette, IN 47907

Phone: 765-494-9601

Email: howell-li@purdue.edu

Jeffrey D. Brooks

Indiana Department of Transportation

100 N senate., IGC N901-Highway Maint. Marion County, Indianapolis, IN 46204

Phone: 317-232-5545

Email: jbrooks27@indot.in.gov

Darcy M. Bullock

Purdue University

207 S Martin Jischke Dr, West Lafayette, IN 47907

Phone: 765-496-2226

Email: darcy@purdue.edu

Submitted October 21, 2020 


\begin{abstract}
The Indiana Department of Transportation (INDOT) operates a fleet of nearly 1100 snowplows and spends up to $\$ 60 \mathrm{M}$ annually on snow removal and de-icing as part of their winter operation maintenance activities. Systematically allocating resources and optimizing material application rates can potentially save revenue that can be reallocated for other roadway maintenance operations. Modern snowplows are beginning to be equipped with a variety of Mobile Road Weather Information Sensors (MARWIS) which can provide a host of analytical data characterizing on-the-ground conditions during periods of wintry precipitation. Traffic speeds fused with road conditions and precipitation data from weather stations provide a uniquely detailed look at the progression of a winter event and the performance of the fleet. This research uses a combination of traffic speeds, MARWIS and North American Land Data Assimilation System (NLDAS) data to develop real-time dashboards characterizing the impact of precipitation and pavement surface temperature on mobility. Twenty heavy snow events were identified for the state of Indiana from November 2018 through April 2019. Two particular instances, that impacted 182 miles and 231 miles of interstate at their peaks occurred in January and March, respectively, and were used as a case study for this paper. The dashboards proposed in this paper may prove to be particularly useful for agencies in tracking fleet activity through a winter storm, helping in resource allocation and scheduling and forecasting resource needs.
\end{abstract}

Keywords: mobility, winter operations, weather, performance metrics, resource allocation 


\section{BACKGROUND}

Winter weather events have a significantly adverse impact on mobility (Day et al., 2016). On average, there are over 5.8 million crashes in the United States every year, of which approximately $21 \%$ are weather-related, and resulting in 418,000 injuries and 5,000 fatalities (Federal Highway Administration, 2018). In 2017 alone, there were a total of 34,247 fatal crashes in the United States, of which 836 were in the state of Indiana (Federal Highway Administration, 2019). Winter weather operations can account for approximately 20 percent of a state Department of Transportation's (DOT) maintenance budget and state and local agencies annually spend upwards of 2.3 billion dollars on snow and ice control operations(Federal Highway Administration, 2018).

Tracking and quantifying the performance of snow and ice control operations is a fairly significant deliverable for agencies and contractors as they strive for improved customer satisfaction. A number of performance measures have been in use worldwide and there is no single widely accepted measure that applies to a variety of road types, storms and traffic conditions. Recovery from event, travel reliability during event, system efficiency and level of customer satisfaction are some of the proposed performance measures in Performance Measures in Snow and Ice Control Operations (Gopalakrishna et al., 2019). Performance metrics prove helpful to agencies in providing guidance with regard to the amount of effort required when planning ahead for a winter event, which in turn helps them better manage costs.

Level of service (LOS) standards have been used to qualitatively gauge winter operations performance in the past. Pavement condition, storm impact, storm severity, accident frequencies, visibility, traffic speed reduction and travel delays are a few examples of winter operations performance metrics that have previously been proposed (Carmichael et al., 2004; Usman, Fu and Miranda-Moreno, 2010; McCullouch, Partridge and Noureldin, 2013; Bandara, 2015). Congestion tickers (referred to as traffic tickers henceforth) have been developed that provide a data archive of real-time and historical congestion on interstate roadways in the state of Indiana (McNamara, 2016). There is a growing consensus in the winter operations field that traffic, weather and road condition data sets should be integrated to provide a comprehensive real-time view of snow and ice control operations during a storm. This has been the primary driving force behind this research.

\section{STUDY MOTIVATION AND SCOPE}

Inclement weather can significantly impact traffic operations, reducing efficiencies of state maintenance vehicles and creating unsafe driving conditions for the public. Advances in the sensors currently deployed to detect roadway conditions provide traffic management agencies with a unique opportunity to anticipate, control and plan ahead to better manage roadways in times of inclement weather. Proactive planning for weather events based on weather forecasts and impact assessment as well as the real-time monitoring of the resources are an important deliverable for agencies.

This study leverages traffic condition, road condition, weather data and geo-location of fleets to develop dashboards for real-time monitoring of winter operations activities and after-action assessment. The dashboards have the potential to provide agencies with a unified look at traffic, weather and pavement conditions in a single interface, thus making resource allocation and scheduling significantly more streamlined when operating off of a unified data source. 
IDENTIFYING WINTER STORMS AND THEIR IMPACTS FOR 2018/19 SEASON TABLE 1 enumerates 20 snow events in the state of Indiana over the period of November 3, 2018 through April 30, 2019. These events were shortlisted based on a value of maximum wintry precipitation (greater than $2 \mathrm{~mm}$ /day) from the North American Land Data Assimilation System (NLDAS) weather stations across the state. TABLE 1 depicts the maximum miles operating below $45 \mathrm{mph}$, observable mobility impact and total mile-hours of congestion across interstate roadways in the state for these events. The storms were further classified as having an observable impact if the maximum miles operating below $45 \mathrm{mph}$ on an event date were over 100 miles. In many cases, these winter events had no significant impact due to a combination of pre-treatment of the roads, precipitation rates low enough that winter maintenance crews could maintain clear roads or pavement temperatures remaining above $32 \mathrm{~F}$. Of the 20 events, 8 storms had a significant impact on Interstate mobility. Two of the events that were identified for further analysis in this paper were moderate winter storms that occurred on January 12 and March 30, 2019.

TABLE 1 Total Mile-Hours of Congestion across all Interstates in Indiana on days with maximum wintry precipitation greater than $2.0 \mathrm{~mm}$

\begin{tabular}{|c|c|c|c|c|}
\hline Event & Date & $\begin{array}{l}\text { Maximum } \\
\text { Miles } \\
<45 \text { mph }\end{array}$ & $\begin{array}{l}\text { Observable } \\
\text { Mobility } \\
\text { Impact (>100 } \\
\text { miles) }\end{array}$ & $\begin{array}{l}\text { Total Mile-Hours of } \\
\text { Congestion }\end{array}$ \\
\hline (i) & $11 / 14 / 2018$ & 84.37 & - & 627.0 \\
\hline (ii) & $11 / 15 / 2018$ & 70.63 & - & 683.7 \\
\hline (iii) & $11 / 19 / 2018$ & 51.70 & - & 360.4 \\
\hline (iv) & $12 / 25 / 2018$ & 27.93 & - & 345.5 \\
\hline (v) & $1 / 11 / 2019$ & 78.40 & - & 351.7 \\
\hline (vi) & $1 / 12 / 2019$ & 181.55 & $\checkmark$ & 1943.7 \\
\hline (vii) & $1 / 13 / 2019$ & 126.54 & $\checkmark$ & 845.6 \\
\hline (viii) & $1 / 19 / 2019$ & 695.75 & $\checkmark$ & 3707.5 \\
\hline (ix) & $1 / 28 / 2019$ & 171.24 & $\checkmark$ & 1009.2 \\
\hline$(\mathrm{x})$ & $2 / 6 / 2019$ & 53.83 & - & 383.8 \\
\hline (xi) & $2 / 10 / 2019$ & 174.16 & $\checkmark$ & 872.0 \\
\hline (xii) & $2 / 12 / 2019$ & 141.43 & $\checkmark$ & 1277.0 \\
\hline (xiii) & $2 / 17 / 2019$ & 83.58 & - & 487.0 \\
\hline (xiv) & 2/19/2019 & 45.84 & - & 312.7 \\
\hline$(\mathrm{xv})$ & $2 / 20 / 2019$ & 155.16 & $\checkmark$ & 832.4 \\
\hline (xvi) & $3 / 30 / 2019$ & 231.08 & $\checkmark$ & 1164.1 \\
\hline (xvii) & $4 / 14 / 2019$ & 61.19 & - & 972.5 \\
\hline (xviii) & $4 / 20 / 2019$ & 46.24 & - & 641.0 \\
\hline (xix) & $4 / 27 / 2019$ & 70.48 & - & 726.8 \\
\hline$(\mathrm{xx})$ & $4 / 28 / 2019$ & 65.17 & - & 756.7 \\
\hline
\end{tabular}


Figure 1a, Figure 1b and Figure 1c are reproductions of the Indiana traffic ticker (Day et al., 2016) on a 6-month and 3-day scale. The Traffic Ticker was developed as a means of helping agencies and maintenance staff get a concise look at how many miles of interstate operated below the performance threshold of $45 \mathrm{mph}$. In this case, it helps visualize and highlight the statewide impact of a winter storm and observe its differential from congestion on a day with zero to low precipitation. The ticker was developed using commercially available crowdsourced probe vehicle speeds. These speeds are obtained on a minute-by-minute basis from aggregation of individual vehicle speeds determined from timestamped positions of GPS-enabled devices, including fleet telematics and cellular phones. For this study, segment definitions from the data provider are used, each approximately 1 mile in length. Speeds on these segments were later aggregated by 15 -minute periods (to reduce minute-by-minute fluctuation of speed) with the median speed in this period used to classify the segment as being congested or not congested for a 15-minute block of time.

Figure 1a depicts miles of Interstate operating below $45 \mathrm{mph}$ across the state of Indiana for the entire winter season with dates ranging from November 3, 2018 to April 30, 2019. The callouts (vi) and (xvi) directly correspond to entries in TABLE 1 for the two aforementioned storms. Figure $1 \mathrm{~b}$ and Figure 1c specifically highlight miles of congestion across the 6 districts in Indiana for the two snow events that are being sampled in this paper. Congested miles or congested conditions in these graphics and in the text that follows are defined as lengths of interstate roadway that are operating below a speed threshold of 45 miles per hour. This threshold has previously been used in the 2015 Indiana Mobility Report (Brennan et al., 2013; Day et al., 2016). Total Mile-Hours of Congestion for the entries in TABLE 1 were computed using Equation 1 (Mekker, 2018).

$$
M H_{<45}=\sum_{i=1}^{n}\left(L_{i} X t_{i}\right)
$$

where,

$M H_{<45}=$ total mile-hours of congestion

$n=$ total number of segments in a stretch of interstate

$L_{i}=$ length of segment $\mathrm{i}$ in miles

$t_{i}=$ duration of time in hours for which segment $\mathrm{i}$ was congested

For the winter storm of January 11-13, 2019, it is observed from Figure $1 \mathrm{~b}$ that peak congestion involved approximately 182 congested miles at 6:30 AM on January 12, 2019. Similarly, peak congestion for the winter storm of March 29-31, 2019 was reached at 8:30 PM on March 30, 2019 with about 231 miles congested across 6 districts. Statewide mile-hours of congestion values reached as high as nearly 1943 mile-hours for January 12 and about 1164 mile-hours of congestion for March 30, 2019. 


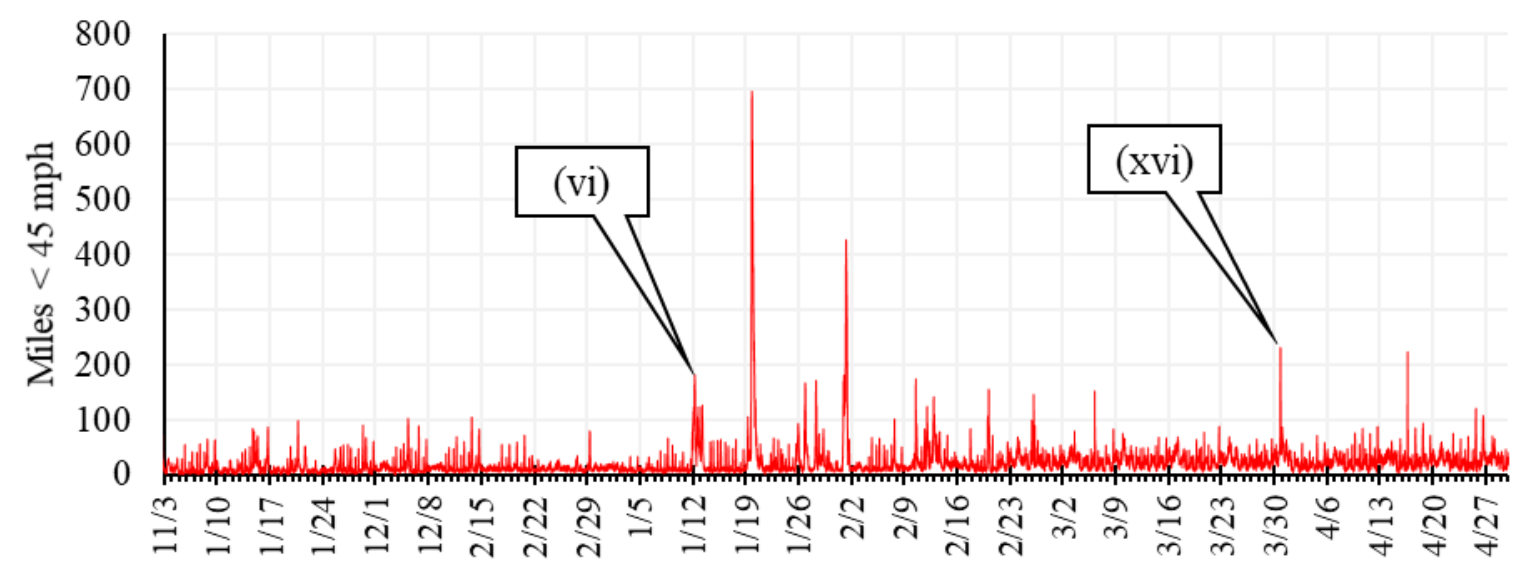

(a) Miles of Indiana Interstates operating below 45mph for 2018/19 Winter Season

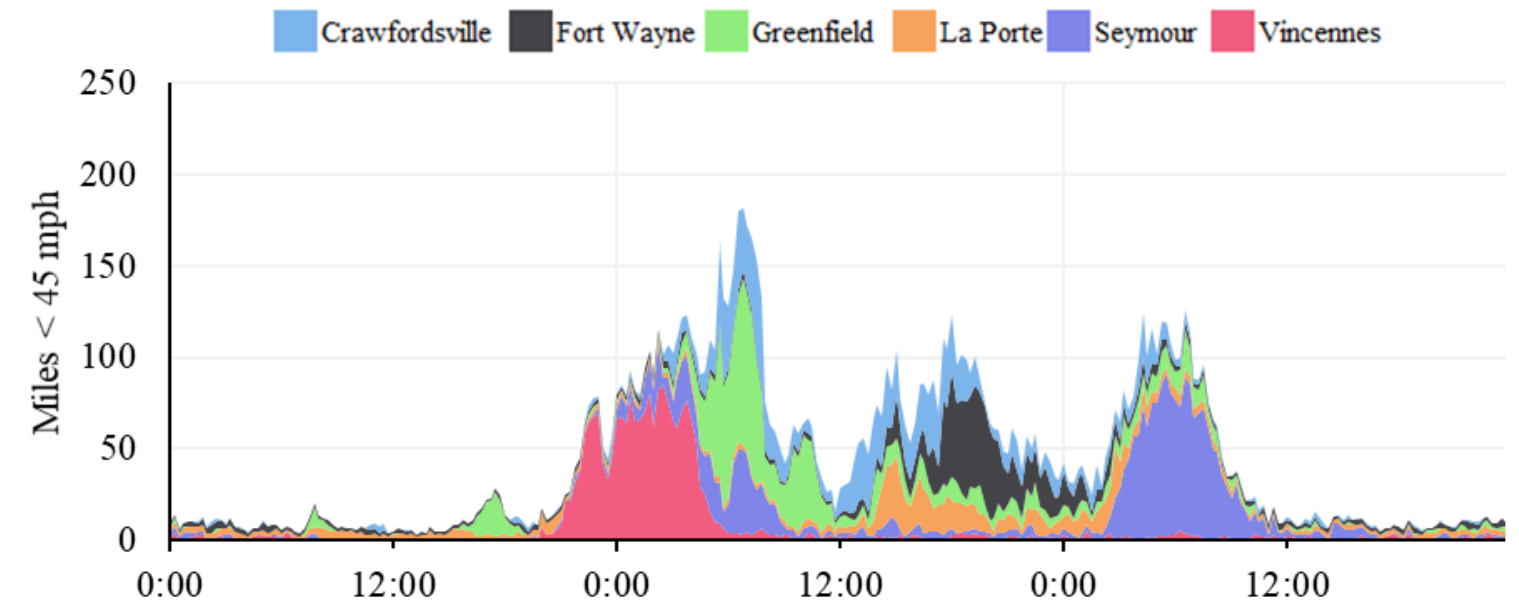

(b) Miles of Interstate operating below 45mph, by district for January $11-13,2019$

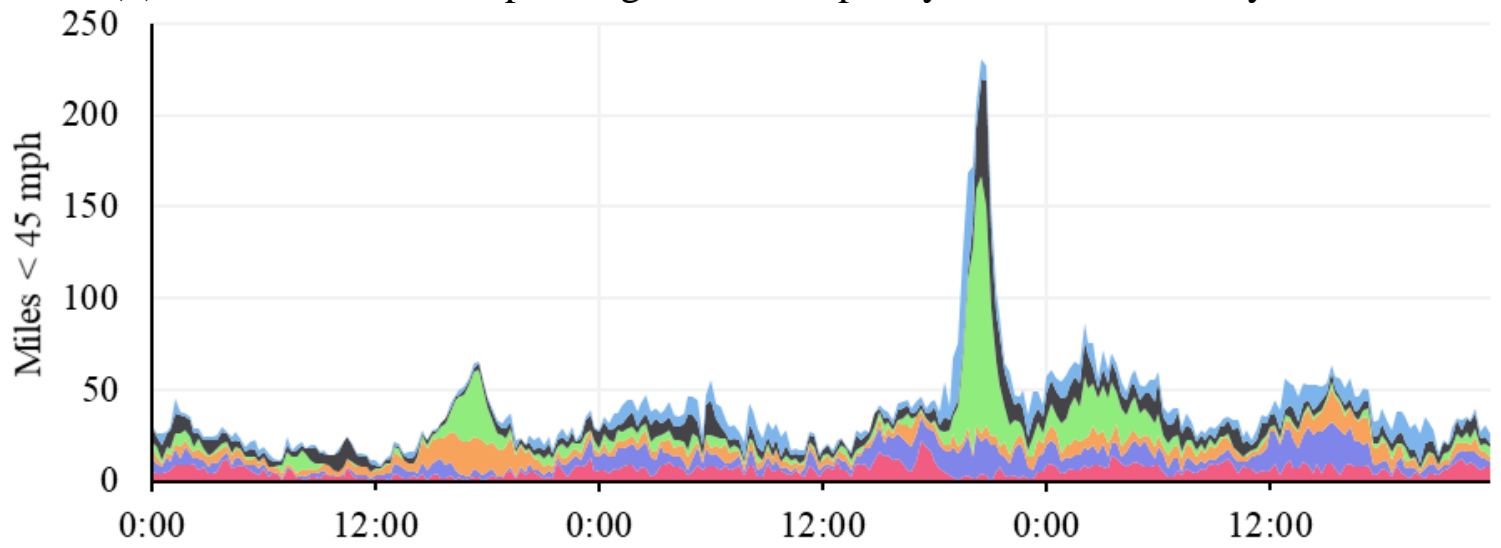

(c) Miles of Interstate operating below 45mph, by district for January March 29 - 31, 2019 Figure 1 INDOT Interstate Traffic Tickers 


\section{ROAD CONDITION AND FLEET LOCATION DATA}

The Indiana Department of Transportation (INDOT) currently operates 14 snow plow trucks outfitted with the Mobile Advanced Road Weather Information System (MARWIS) sensor (Figure $2 \mathrm{a}$ and Figure $2 \mathrm{~b}$ ). The sensors collect geo-location data including latitude, longitude and altitude along with speeds and heading. In addition, they estimate road condition from the measured parameters, which includes dew point, surface temperature, friction, ice percent, relative humidity and water film height. The data coming in from these trucks at 5-second frequency constitutes an important data set that is a significant bellwether of pavement friction conditions.

Figure 2c illustrates a sample view of a commercially available dashboard that shows the activity of a snow plow truck with its trajectory color coded by the road condition. Data shows stretches of I-465 being in icy or chemically wet conditions during the winter storm on January 12, 2019. While the two storms that are presented in the sections to follow showed a moderate impact on mobility, they were chosen due to the near complete coverage of MARWIS data available from snow plows on those dates. Additionally, the contrast in the winter weather maintenance strategy for these dates made them ideal candidates for this research. 


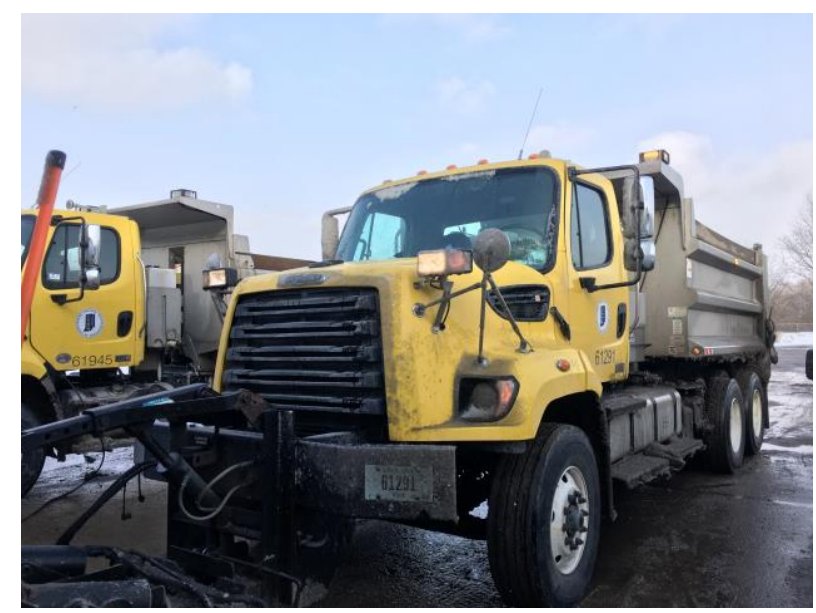

(a) INDOT Snowplow

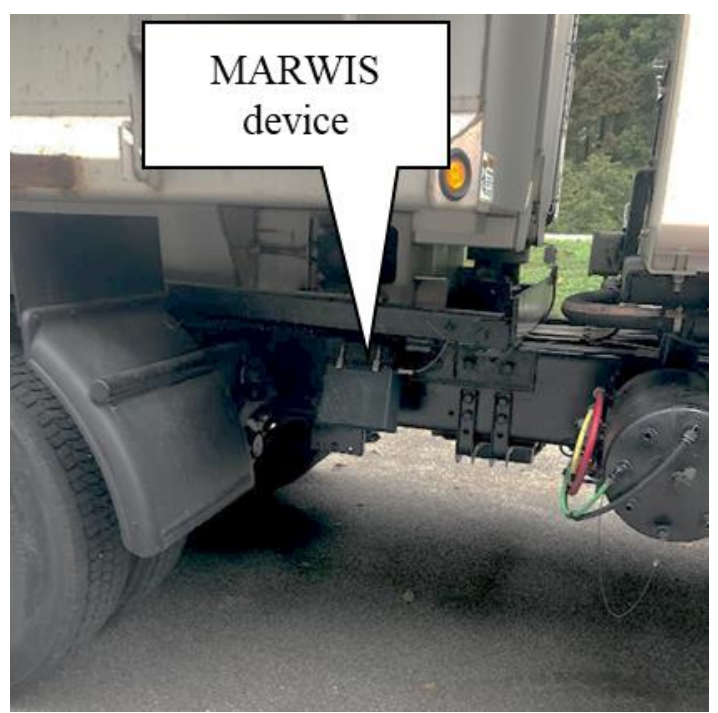

(b) Mounted MARWIS sensor

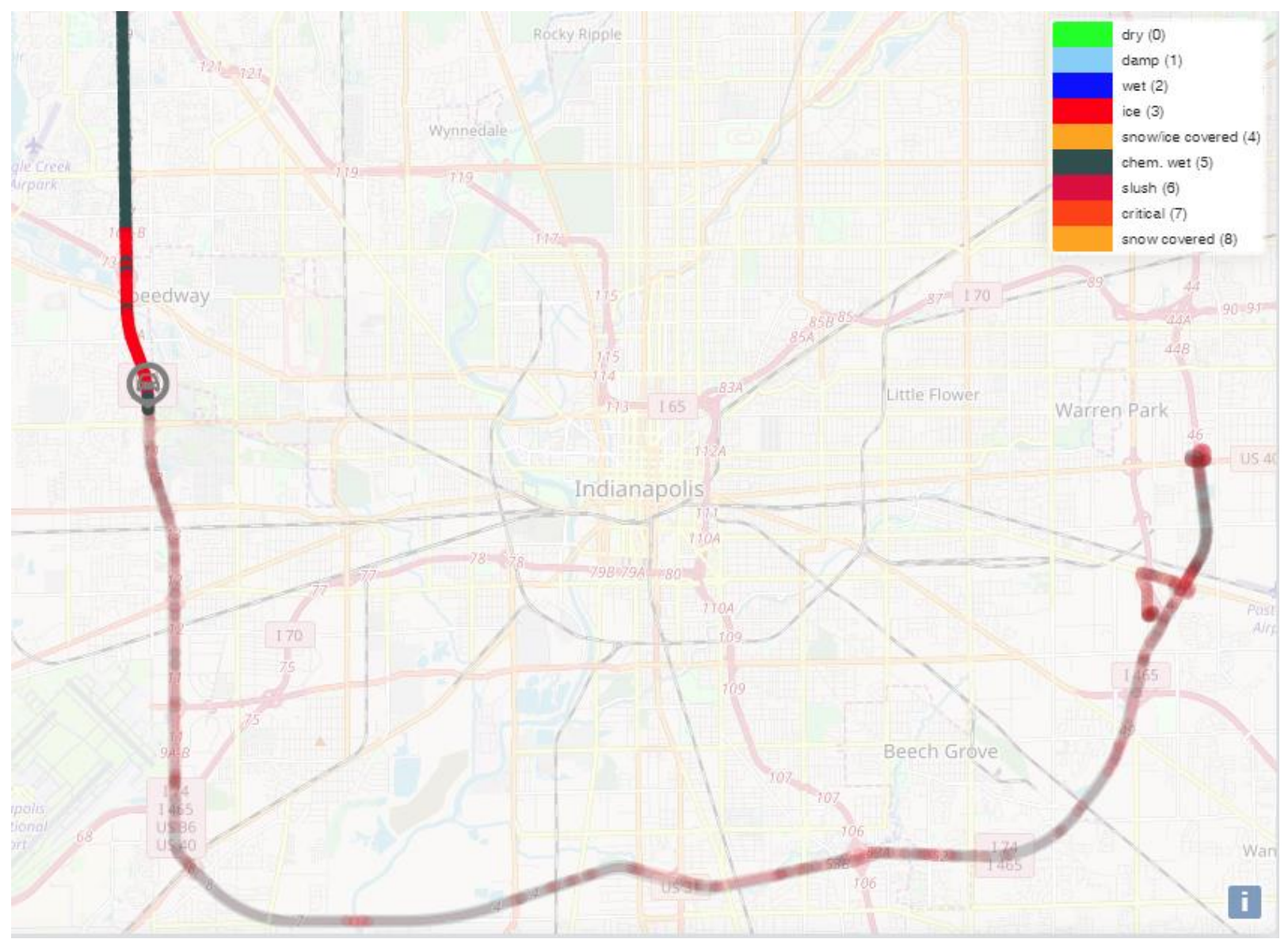

(c) Web dashboard showing truck's location on I-465 and road condition on January 12,2019 from MARWIS

Figure 2 MARWIS sensor and road condition data 


\section{SPEED PROFILE HEAT MAPS DASHBOARD WITH ROAD CONDITIONS}

Figure $3 \mathrm{a}$ and Figure $3 \mathrm{~b}$ show traffic ticker views for the 53 mile section of I-465, color coded by speed on 12 January, 2019. The heat maps in Figure 3c and Figure 3d show traffic speeds spatially along the 53 mile section of I-465 in 15 minute intervals throughout the day for both the inner loop (clockwise) and outer loop (counter clockwise). The horizontal black lines on the heat maps indicate mile-marker locations where INDOT TrafficWise cameras have been positioned and realtime images from the same can be obtained when hovering over these camera lines.

Moderate congestion can clearly be seen in both directions of travel in the stretch of 4 AM through 11 AM. Figure 3a and Figure 3b show vehicle speeds from data obtained through the traffic ticker for the 53-mile stretch of I-465 in both directions of travel and also highlight the same period of congestion as observed on the heat maps in Figure 3c and Figure 3d. The outer loop showed a peak congestion of nearly 27 miles at 6:30 AM, while the inner loop showed roughly 24 congested miles at 7:30 AM.

Figure $3 \mathrm{e}$ and Figure $3 \mathrm{f}$ shows the same traffic speed heat maps as in Figure $3 \mathrm{c}$ and Figure $3 \mathrm{~d}$ but with an added overlay of geo-location trajectories from the snowplows color coded by the road friction value recorded on the MARWIS sensors from Figure 2c. The friction values are seen to be decreasing as the storm sets in, and after multiple passes of the snowplow trucks the friction eventually improves to an acceptable level by the evening of the same day. INDOT snow plows in this case began pre-treating before the onset of the snow storm in the early hours of January 12. They continued treating and plowing the road all through the storm and only halted when wintry precipitation had completely stopped. Although these heat maps have been created as an afteraction tool by superimposing the MARWIS trajectories, they could easily be implemented in realtime as well.

These road condition parameters coupled with traffic speeds present an accurate and localized view of the impact of a winter storm on mobility on a particular stretch of roadway and help agencies in the decision-making process. The data in Figure 3a,Figure 3c and Figure 3e corresponds to the I-465 outer loop while Figure 3b, Figure $3 d$ and Figure $3 f$ correspond to the I465 inner loop. For example, callout $\mathrm{i}$ in Figure $3 \mathrm{f}$, corresponds to a truck travelling from mile marker 0 to mile 20 around 2 AM. This particular trajectory is mostly green, indicating good friction. The subsequent trajectory (Figure 3f, callout ii) occurs around 4 AM and shows a significant amount of red, indicating extremely bad friction and one can see the speed profile heat map shows traffic slowing significantly. 


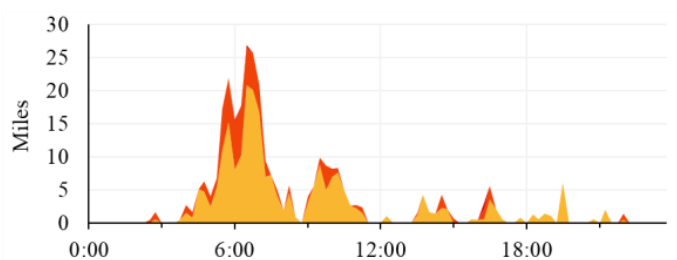

(a) Traffic ticker for I-465 Outer Loop MM 0-53

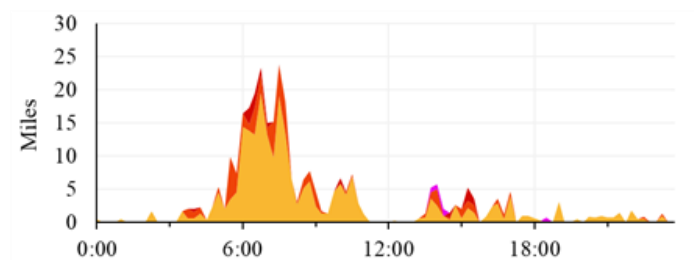

(b) Traffic ticker for I-465 Inner Loop MM 0-53

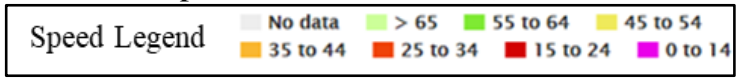

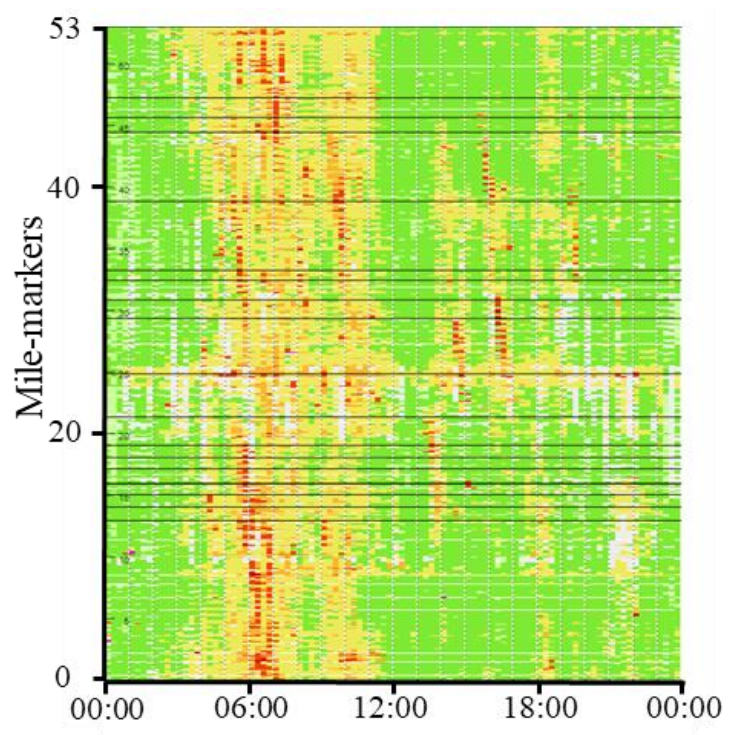

(c) Speed profile heat maps for I-465 Outer Loop

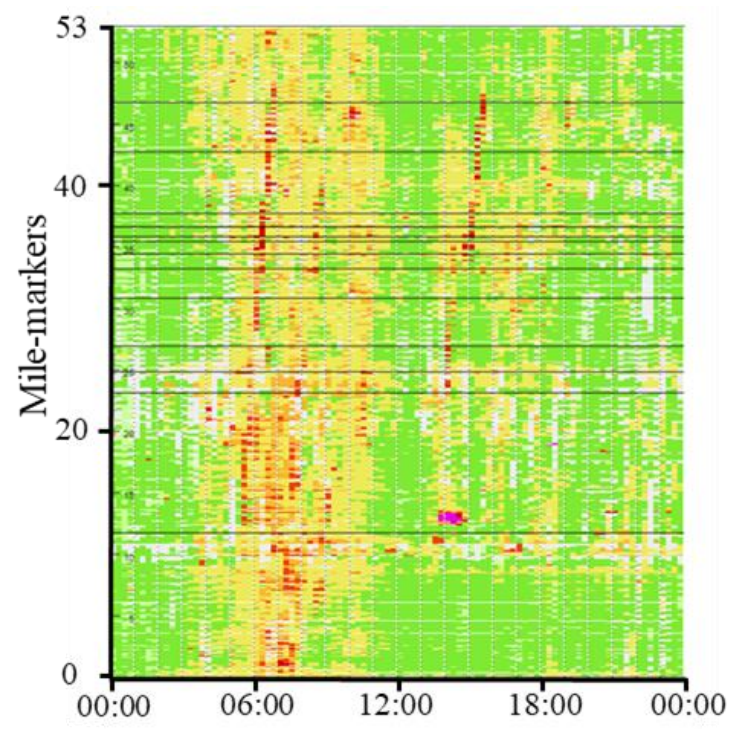

(d) Speed profile heat maps for I-465 Inner Loop

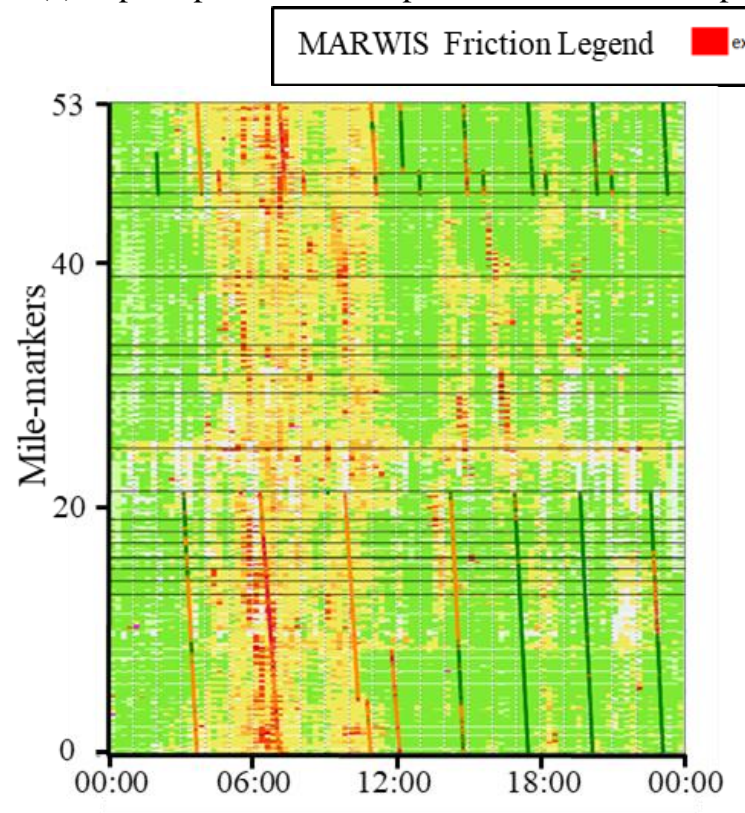

(e) Speed profile heat maps for I-465 Outer Loop with MARWIS friction trajectories extremely bad $[0,0.4) \_$caution $[0.4,0.75) \square \operatorname{good}[0.75,1]$

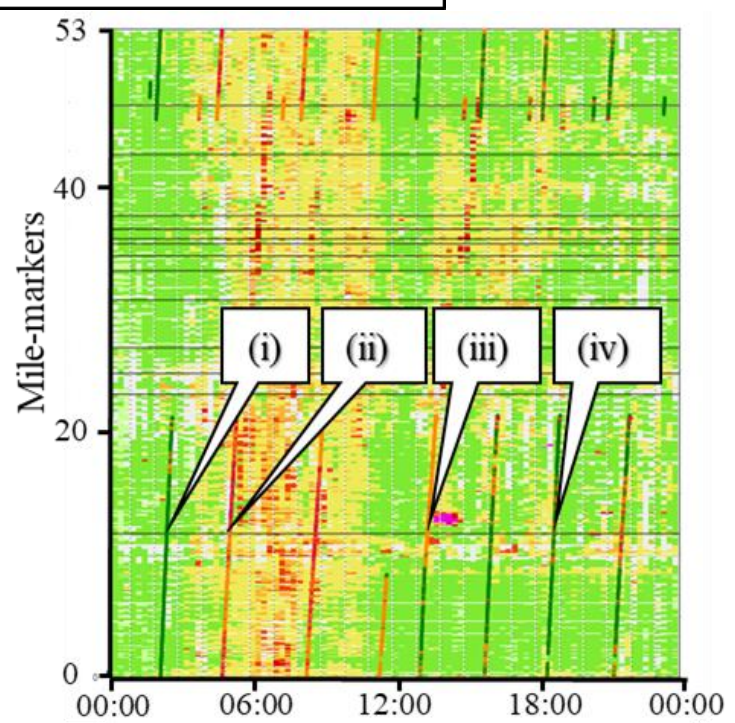

(f) Speed profile heat maps for I-465 Inner Loop with MARWIS friction trajectories

Figure 3 Speed profiles shown by heat maps and traffic ticker, along with overlaid MARWIS trajectories color coded by friction for I-465 MM 0-53 January 12, 2019 
Figure 4 shows corresponding traffic camera images for callouts (i), (ii), (iii) and (iv) placed on Figure 3f. This traffic camera is situated at mile marker 11.7 on the I-465 Inner Loop and the images below show a clear progression of friction conditions from the onset of the storm through recovery to normal traffic and uncongested conditions following snowplow activity throughout the day. Starting out with good friction values during the first pass (Figure 4a) around 2:30AM, the friction worsened over the next couple of hours due to low overnight temperatures as well as reduced traffic activity as shown by Figure 4b. After nearly 6 passes, friction improved to an ideal range and Figure $4 \mathrm{~d}$ illustrates the clear road conditions in support of the same. This shows ideal coverage of the interstate by snow plows resulting in recovery from the storm to ideal road conditions on the very same day in a span of a few hours.

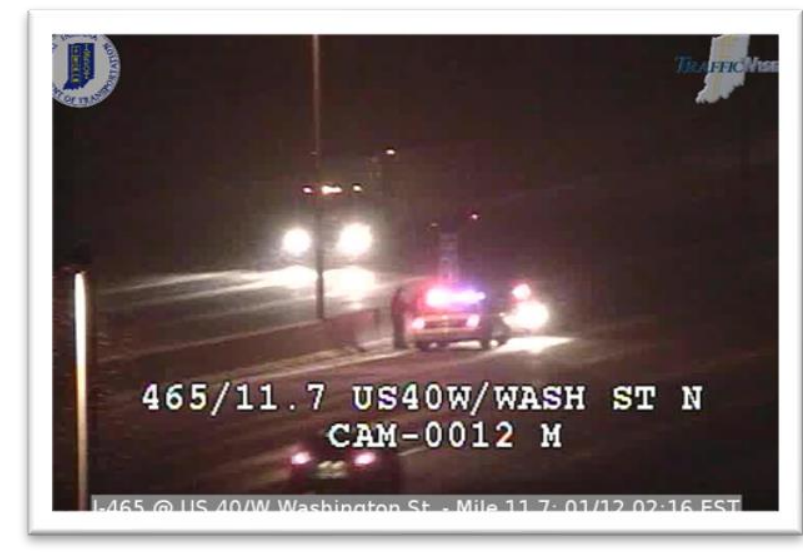

(a) Good friction conditions at 2:16 AM corresponding to callout (i)

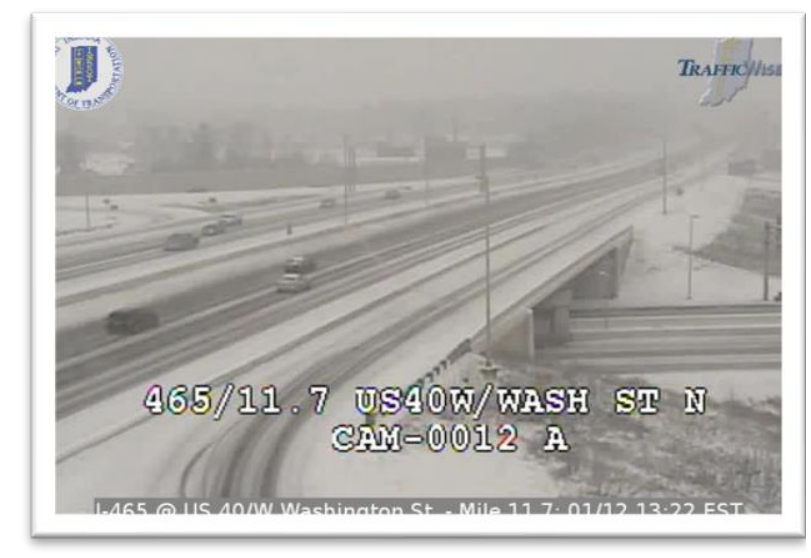

(c) Friction improving at 1:22 PM corresponding to callout (iii)

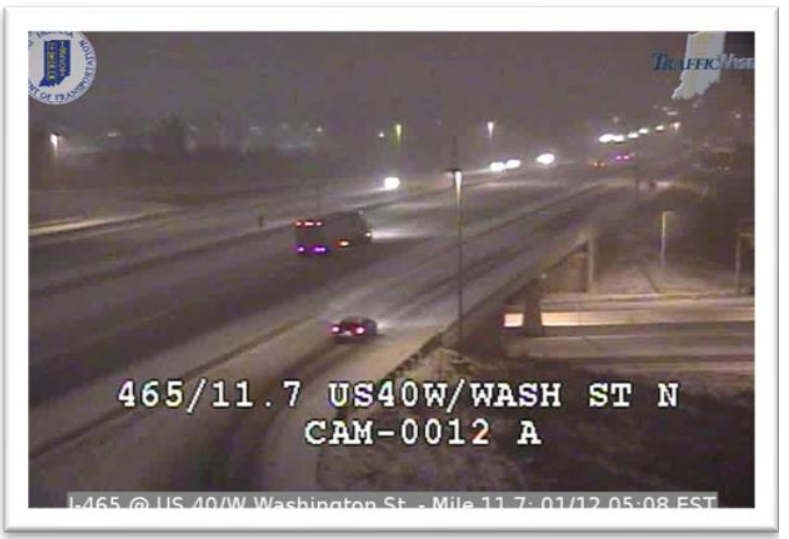

(b) Friction worsens with snow at 5:08 AM corresponding to callout (ii)

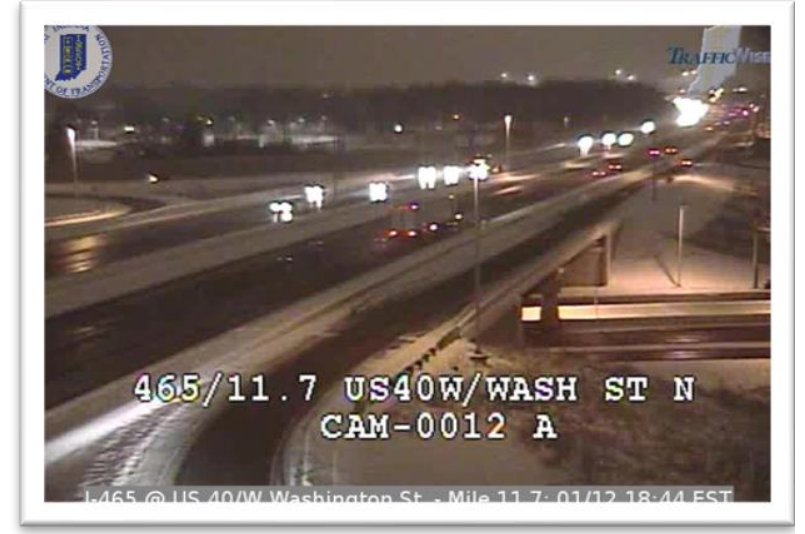

(d) Good friction conditions at 6:44 PM corresponding to callout (iv)

\section{Figure 4 Traffic camera images showing roadway conditions from Figure $3 f$}

Figure 5 shows a similar representation of speed profiles as shown in Figure 3, but for the winter storm of March 30, 2019 on interstate I-70 from mile marker 88 to 109. From the snow plow trajectory overlays it is evident that the fleet was late in catching up to the winter storm on March 30 and only started plowing and applying material when congestion on this stretch of roadway was at its peak value. To understand why the winter operation fleet was deployed after traffic speeds begin to deteriorate, it is important to consider the weather conditions that led to this storm. 


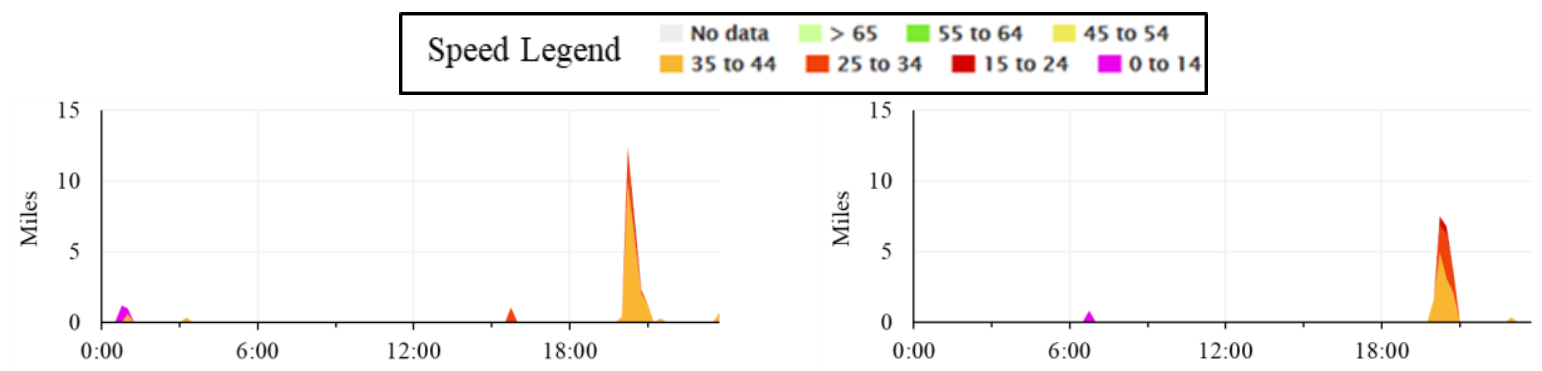

(a) Traffic ticker for I-70 Westbound

(b) Traffic ticker for I-70 Eastbound

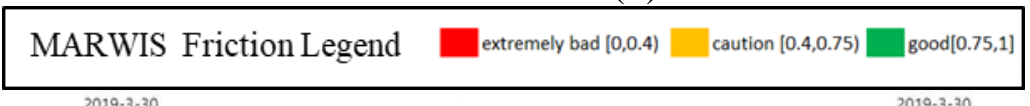

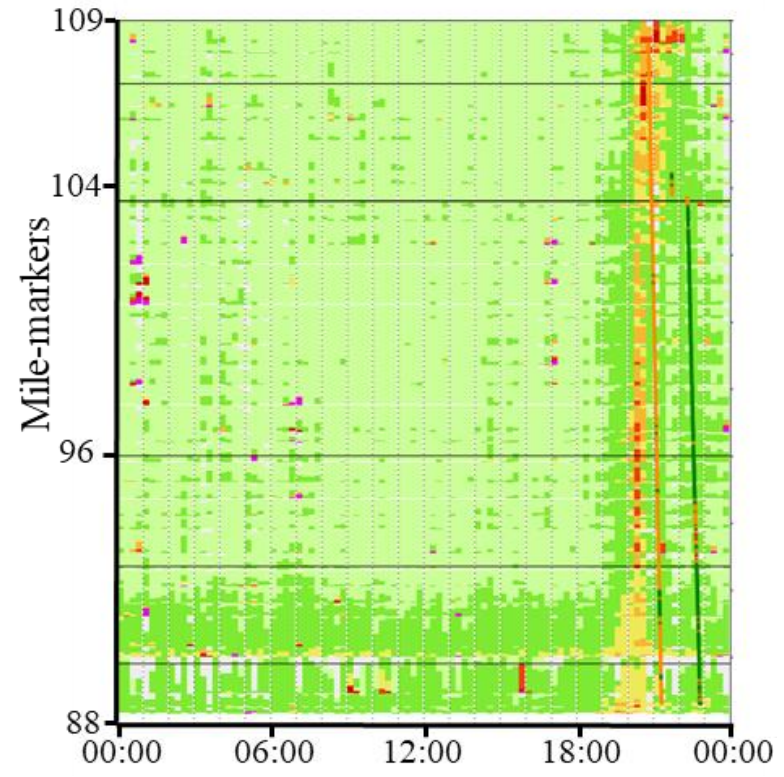

(c) Speed profile heat maps for I-70 WB with MARWIS friction trajectories

Figure 5 Speed profiles shown by heat maps and traffic ticker, along with overlaid MARWIS trajectories color coded by friction for I-70 MM 88-109 March 30, 2019 INTEGRATION OF WEATHER DATA WITH ROAD CONDITIONS

Improvements in weather prediction and forecasting models carry immense value for state agencies who can use these advances for efficient resource allocation, scheduling and maintaining roadways during heavy precipitation events. Studies have found precipitation rate to be one of the most important weather variables to have an effect on road safety (Koetse and Rietveld, 2009). Most studies do tend to indicate a positive relationship between precipitation and frequency of road accidents (Chung et al., 2005).

Figure 6 offers a comprehensive look at traffic and weather data in a suite of dashboards to directly visualize how a sustained precipitation event followed by reduction in temperature impacted the road and traffic conditions. The graphics in Figure 6a, Figure 6c, Figure 6e and Figure 6g pertain to the January 12 storm on I-465 outer loop direction from Figure 3a, Figure $3 \mathrm{c}$ and Figure 3e. The plots in Figure 6b,Figure 6d,Figure 6f and Figure 6h correspond to the March 30 storm on I-70 
west bound direction from Figure 5a and Figure 5c. Figure 6a, Figure 6b, Figure $6 \mathrm{c}$ and Figure $6 \mathrm{~d}$ were plotted using data obtained from NLDAS sensors near the respective stretches of interstate. Figure $6 \mathrm{a}$ and Figure $6 \mathrm{~b}$ depict the median average surface skin temperature on an hourly fidelity for the two winter storms. Figure $6 \mathrm{c}$ and Figure $6 \mathrm{~d}$ depict the median amount of wintry precipitation in millimeters again on an hourly granularity for these two storms. The precipitation amount has been split into rain and wintry precipitation amounts to exactly pinpoint the onset of each snow storm.

Directly comparing Figure $6 \mathrm{c}$ and Figure $6 \mathrm{~g}$ for the first winter storm, it is observed that the snow plows operated very much in tandem with the winter storm on January 12, 2019 and in fact had begun operating just as soon as wintry precipitation amounts were beginning to rise on I-465. They continued roadway maintenance activity throughout the day until the storm died out and wintry precipitation amounts were declining towards the end of the day, with a subsequent effect seen in better pavement friction values on I-465. Wintry precipitation first began between the hours of 2:00 AM and 3:00 AM on January 12, and the first pass of the snow plow on this route was also in the same time period thus showing good storm coverage by INDOT in this instance.

The same comparison for the March 30 storm shows that while wintry precipitation began between 6:00 PM and 7:00 PM, the snow plows were deployed around the 9:00 PM mark, at a time when wintry precipitation was at its peak value of $2.4 \mathrm{~mm}$. Due to this, congestion had already significantly built up on I-70 as can be seen from Figure $6 \mathrm{f}$ and Figure $6 \mathrm{~h}$ before the plowing and road treatment activity. During the March storm, the elevated temperatures and precipitation would have washed away any pre-treatment and the pavement temperature was not forecast to drop below freezing during the precipitation event. As seen in Figures $6 \mathrm{~b}$ and Figure $6 \mathrm{~d}$, the sudden drop in temperatures resulted in the transition to wintry precipitation from rain. Such events are very difficult to forecast in advance. A more accurate forecast would have provided the opportunity for earlier coverage by the snow plow fleet that could potentially have alleviated some of the congestion that occurred which at its peak was nearly 15 congested miles on I-70 in a 21-mile stretch of road. It was also observed that the traffic ticker plots in Figure 6e and Figure 6f follow the same general trend as the wintry precipitation plots in Figure $6 \mathrm{c}$ and Figure $6 \mathrm{~d}$ thus showing a direct impact of adverse weather conditions resulting in congested stretches of interstate.

Although weather forecasts will never be $100 \%$ accurate, dashboards such as these provide a framework for winter operations staff to monitor conditions, perform after action assessment, and provide improved feedback to forecast modeling colleagues. 


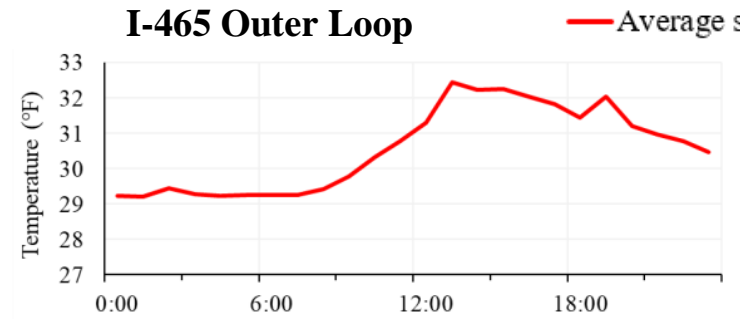

(a) I-465 OL MM 0-53 1/12
I-70 West Bound

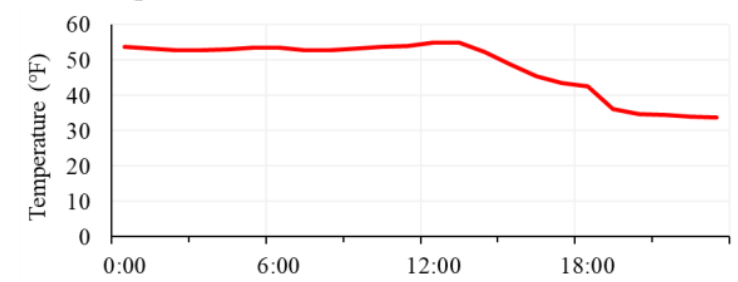

(b) I-70 WB MM 90-116 3/30

Wintry Precipitation -Rain

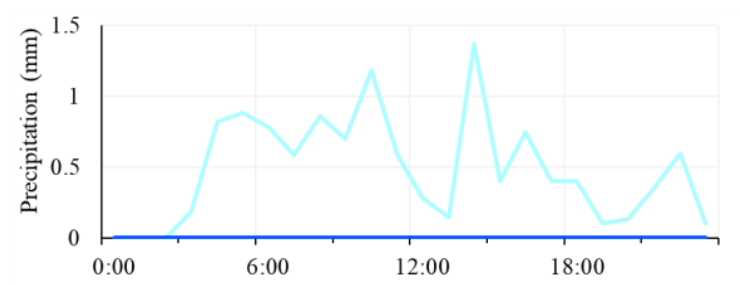

(c) I-465 OL MM 0-53 1/12

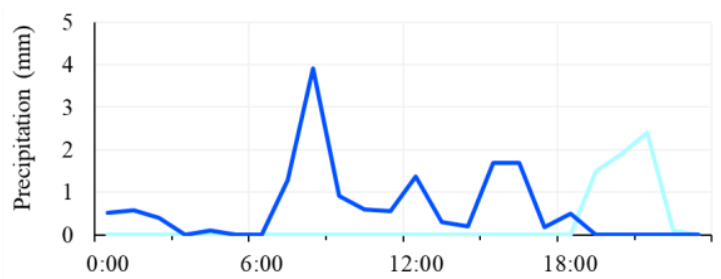

(d) I-70 WB MM 90-116 3/30

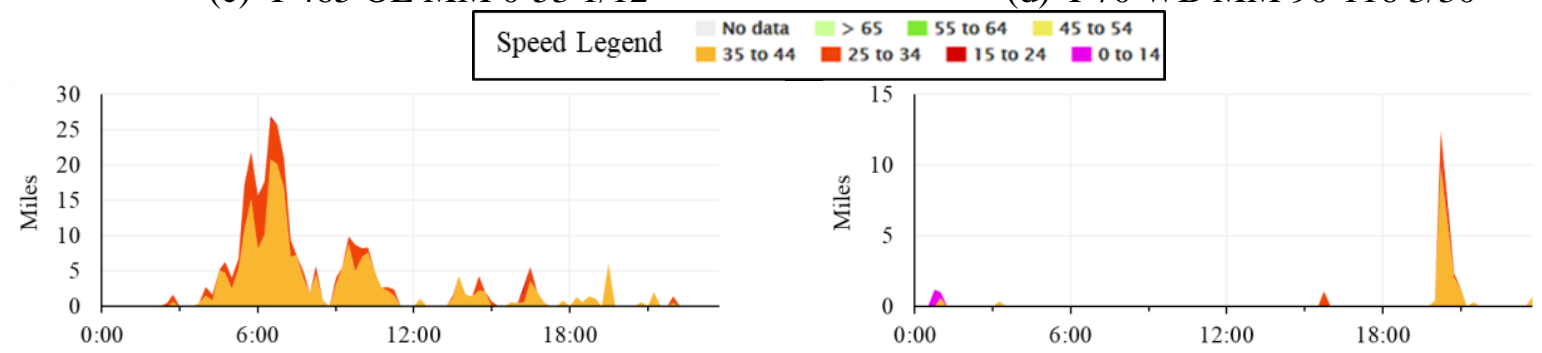

(e) Traffic ticker I-465 1/12 MM 0-53

(f) Traffic Ticker I-70 3/30 MM 88-109

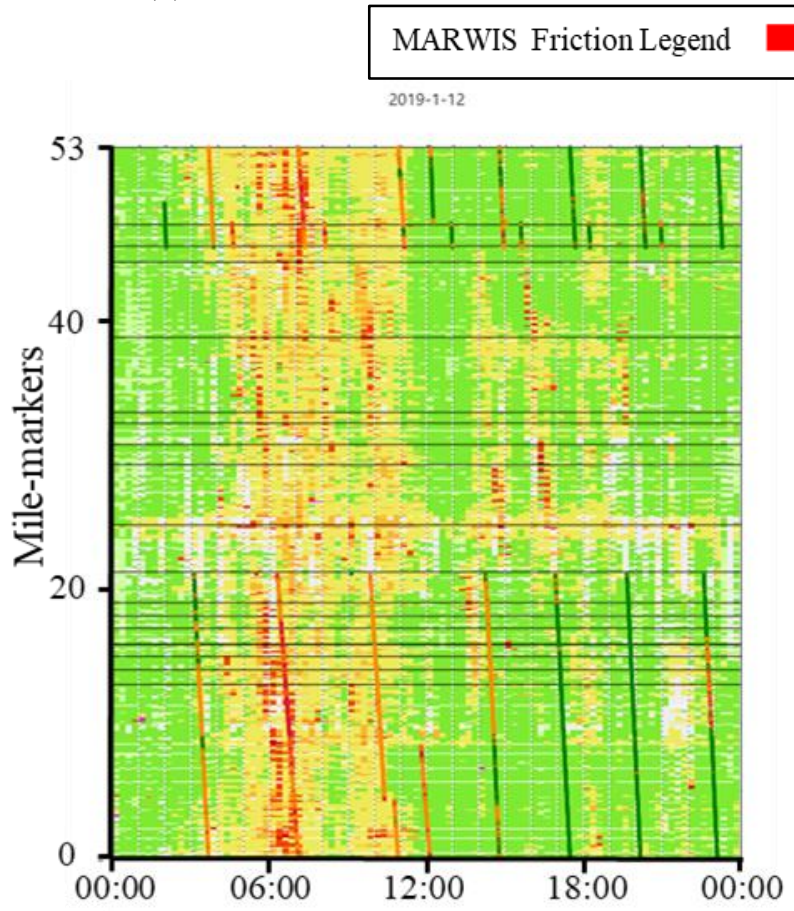

(g) MARWIS trajectories on heat maps for I-465 OL 1/12 MM 0-53

extremely bad $[0,0.4) \square$ caution $[0.4,0.75) \square \operatorname{good}[0.75,1]$

2019-3-30

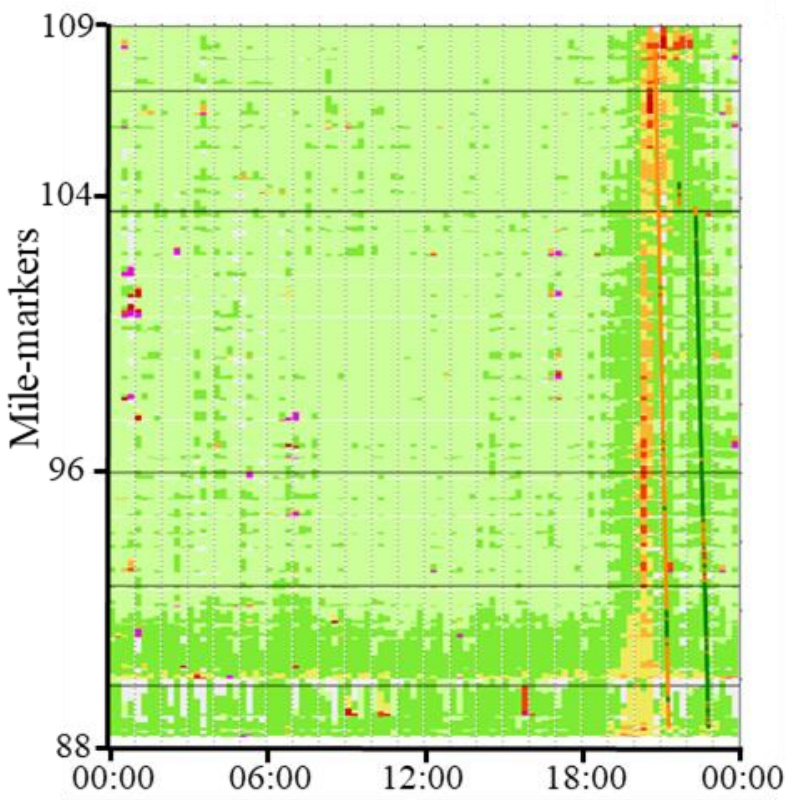

(h) MARWIS trajectories on heat maps for I-70 WB 3/30 MM 88-109

\section{Figure 6 Traffic and Weather Data for 2 Winter Storms showing inflection points}




\section{SUMMARY}

This study began with the identification of twenty winter storm events from November 2018 to April 2019 using NLDAS precipitation data. These storms were classified as being of observable mobility impact if the peak congested miles on the event days were over 100 miles (TABLE 1). Two storms with moderate observable impact, with a marked difference in statewide impact, as well as snow plow coverage were then explored in detail. The two cases highlighted situations wherein snow plows covered and treated roadways for a storm well in advance (Figure 3 ) as well as when snow plows lagged the storm by a couple hours (Figure 5) leading to delayed maintenance activity. A suite of dashboards was presented that compiled traffic, road condition and weather data all into one providing a unique solution for agencies towards real-time tracking for winter weather operations (Figure 6).

These web dashboards can clearly show the impact and efficiency of winter weather maintenance activity before, during and after a storm and can also prove as a medium for tracking an agency's snow plow fleet in real-time with the progression of a storm. Snow plows can provide data from on-board controllers (plowing and salting) as well as externally fitted mobile road weather devices. However, telemetry will be an important factor moving forward, as these data sets will help agencies and stakeholders to understand the changing on-the-ground conditions in real-time and optimize winter weather maintenance strategies. Less than ideal friction conditions can be detected from enhanced probe vehicle data including brake pressure, anti-lock brake (ABS) activation or traction control intervention and can be validated by the ground-truth MARWIS readings. With OEMs starting to capture these enhanced probe data (Li et al., 2019), agencies and DOTs will have a complete picture of the road conditions without having to depend solely on weather forecast models.

Moving forward, these dashboards can also be used to quantify a number of performance metrics. The recovery from event performance metric can be computed with the help of the snow plow trajectories as they track pavement friction values in real-time and can exactly pinpoint the beginning and ending of an event based on the pavement friction value dipping below a certain pre-defined number. Safety is another performance metric that can be tracked using these dashboards, as linking a crash database to highlight crash events on the heat maps can be easily done, or speed profile minimums could be set that indicate a temporary road closure due to a crash. Apart from pavement friction, MARWIS devices offer a number of parameters in real-time, each of which could be used as a performance measure to gauge whether a stretch of roadway has recovered from a winter event.

Lastly, multi-variate Autoregressive Integrated Moving Average (ARIMA) forecasting models could be developed based on the three data sets observed in this paper - traffic (speeds), weather (surface skin temperature and precipitation amount) and MARWIS (trajectories, weather data) to be able to forecast traffic conditions on a winter event day and how they would be impacted by precipitation using historical data. This can prove to be an effective weather prediction tool for agencies which will eventually help them better allocate and schedule their resources in advance of a snow event leading to an overall improvement in winter weather mobility. 


\section{ACKNOWLEDGEMENTS}

This research used MARWIS data supplied by The Hoosier Company, probe vehicle data provided by INRIX, web dashboards developed by the Joint Transportation Research Program at Purdue University, West Lafayette, IN and traffic camera images provided by INDOT TrafficWise. This work was supported by the Joint Transportation Research Program and the Indiana Department of Transportation. The authors would like to thank Josh Coulter and The Hoosier Company for their continued support throughout this research. The contents of this paper reflect the views of its authors, who are responsible for the facts and accuracy of the data presented herein, and do not necessarily reflect the official views or policies of the sponsoring organizations. These contents do not constitute a standard, specification or regulation.

\section{AUTHOR CONTRIBUTION}

The authors confirm contribution to the paper as follows: study conception and design:

Darcy Bullock, Jeffrey Brooks, Howell Li; data collection: Jairaj Desai, Mingmin Liu, Woosung Kim; analysis and interpretation of results: Jairaj Desai, Woosung Kim, Jijo Mathew, Darcy Bullock; draft manuscript preparation: Jairaj Desai, Jijo Mathew, Howell Li, Darcy Bullock, Jeffrey Brooks. All authors reviewed the results and approved the final version of the manuscript.

\section{REFERENCES}

Bandara, N. Winter Travel Speed Data as Performance Measures for Winter Operations, in Cold Regions Engineering 2015. Reston, VA: American Society of Civil Engineers, 2015. pp. 452463

Brennan, T. M. et al. Probe Vehicle-Based Statewide Mobility Performance Measures for Decision Makers. Transportation Research Record: Journal of the Transportation Research Board, 2015. 2338(1): 78-90

Carmichael, C. G. et al. A Winter Weather Index for Estimating Winter Roadway Maintenance Costs in the Midwest. Journal of Applied Meteorology, 2004. 43(11): 1783-1790

Chung, E. et al. Effect of rain on travel demand and traffic accidents, in IEEE Conference on Intelligent Transportation Systems, Proceedings, ITSC, 2005. pp. 1080-1083

Day, C. M., McNamara, M. L., Li, H., Sakhare, R. S., Desai, J., Cox, E. D., Horton, D. K., \& Bullock, D. M. 2015 Indiana mobility report and performance measure dashboards. West Lafayette, IN: Purdue University, 2016. http://dx.doi .org/10.5703/1288284316352

Federal Highway Administration. How Do Weather Events Impact Roads? U.S. Department of Transportation. https://ops.fhwa.dot.gov/weather/q1_roadimpact.htm. Accessed Jul. 24, 2019. Federal Highway Administration. Roadway Safety Data Dashboards. U.S. Department of Transportation. https://rspcb.safety.fhwa.dot.gov/Dashboard/Default.aspx. Accessed Jul. 24, 2019.

Gopalakrishna, D. et al. Performance Measures in Snow and Ice Control Operations. Transportation Research Board, Washington, D.C, 2019. http://dx.doi.org/10.17226/25410 Koetse, M. J. and Rietveld, P. The impact of climate change and weather on transport: An overview of empirical findings. Transportation Research Part D: Transport and Environment, 2009. 14(3): 205-221

Li, H. et al. Leveraging Connected Vehicles to Provide Enhanced Roadway Condition Information. Presented at 98th Annual Meeting of the Transportation Research Board, Washington, D.C., 2019 
McCullouch, B., Partridge, B. and Noureldin, S. Snow and Ice Performance Standards. Publication FHWA/IN/JTRP-2013/21. Joint Transportation Research Program, Indiana Department of Transportation and Purdue University, West Lafayette, Indiana, 2013. McNamara, M. Real-Time Probe Data Dashboards for Interstate Performance Monitoring During Winter Weather and Incidents, in Automated Traffic Signal Performance Measure Workshop. Purdue University, 2016. doi: 10.5703/1288284316062.

Mekker, M. Connected vehicle data-based tools for work zone active traffic management. Purdue University, 2018.

Usman, T., Fu, L. and Miranda-Moreno, L. F. Quantifying safety benefit of winter road maintenance: Accident frequency modeling. Accident Analysis and Prevention, 2010. 42(6):

$1878-1887$ 